\title{
Violence against Children: A Critical Issue for Development
}

\author{
Anke Hoeffler \\ Centre for the Study of African Economies \\ Department of Economics \\ University of Oxford \\ anke.hoeffler@economics.ox.ac.uk \\ Draft September 2017 \\ Forthcoming in the European Journal of Development Research
}

I would like to thank Laura Camfield, Nicola Boydell, James Fearon, Godfrey Siu, Eve Puffer, Mariette de Haan, Vanessa Watson and Daniel Wright for helpful comments and suggestions. Asfandyar Mir provided excellent research assistance. The project was supported by a grant from the John Fell Fund. All remaining errors are my own. 


\begin{abstract}
Violence against children is a human rights challenge and according to the UN Sustainable Development Goal 16.2 all violence against children should be eliminated. This paper discusses how violence against children can be defined and which forms it takes. Parental violence in the form of physical discipline is highly prevalent, in particular in low income countries. This violence causes suffering, has serious health consequences and reduces human capital. This article estimates that 311 million children are subjected to severe forms of physical punishment, this is equivalent to 17.5 per cent of all children worldwide. In contrast to other forms of violence (e.g. civil wars and terrorism) 'every day' violence against children receives little attention in development research, despite the high prevalence rates and resulting adverse consequences for societal development. This special issue presents evidence from promising parenting interventions for violence reduction in low income settings in Kenya, Liberia and Uganda.
\end{abstract}




\section{Introduction}

Improving children's lives is a global aspiration and the United Nations sets out legally binding standards in the Convention on the Rights of the Child. This convention has received resounding support, 196 members have ratified it - more than any other convention. The UN's 2030 Agenda for Sustainable Development also underscores the importance of protecting children, one of the goals is to "end all violence against ... children" (SDG 16.2). Sadly the reality is very different to the UN's aspirations: Many children are subjected to violence.

There is a large empirical literature showing that childhood exposure to violence does not only cause immediate pain and suffering but has life-long consequences (Sara and Lappin 2017). Violence disrupts social and psychological learning processes (Straus et al 2014) and impacts negatively on brain development (Danese and Baldwin 2017; Nemeroff 2004, 2012). ${ }^{\mathrm{i}}$ Individuals suffer from adverse mental and physical health outcomes and are less likely to reach their full potential and they are also more likely to engage in antisocial and violent behaviour. Thus, in the aggregate violence against children has negative consequences for societal and economic development. However, the link between violence and societal development is complex: Violence against children is more prevalent in poorer countries (Fearon and Hoeffler 2014), suggesting that societal development is not only a consequence but also a driver of violence. However, as the articles in this special issue suggest, even in very poor societies violence against children can be reduced.

Violence against children is not only a violation of human rights and problem of public health but also a critical issue for development. The aim of this editorial is to highlight the importance of violence against children for societal development and the argument is presented in three parts. The first section suggests a broad definition of what constitutes violence against children. Although some violence against children receives considerable media attention (e.g. female genital mutilation/cutting, early marriages, child prostitution, child pornography, child soldiers), most of the violence happens in the home (Pinheiro 2006). The main focus should therefore be on reducing parental violence against children. The second section provides global and regional estimates of the magnitude of the problem. Based on the existing evidence from the MICS I estimate that globally about 17.5 per cent of all children receive severe corporal punishment in their homes every month and the prevalence of such disciplining methods is 
considerably higher in low income countries. The third section provides an overview of the societal consequences of violence against children. While there is overwhelming empirical evidence of the harmful effects of violence against children on societal development, this literature can be characterized as follows. First, there is so far no theoretical literature linking violence against children and societal development. Second, most of the empirical evidence comes from high income countries but we argue that this research and the limited evidence from low income societies points in the same direction: parental violence harms the individual child but also has longer term consequences for societal development. This overview of the evidence is followed by a discussion of violence reduction strategies. Parenting programs have been successful in reducing harsh parenting in high income countries but so far only a few studies in low income countries exist (Knerr et al 2013). For this special issue leading child psychologists and anthropologists present the evidence from parenting programs in low income settings in five complementary papers. The programs in rural Liberia (Giusto et al), rural and peri-urban Uganda (Siu et al) and rural Kenya (Van Esch and De Haan) suggest that parental attitudes and behaviour changed, resulting in reducing violence against children. The strength of these studies is that they provide detailed qualitative evidence of why parents participating in parenting programmes use violence, and what makes the programmes effective in a specific setting. It is important to point out that the studies are small-scale and are not considered representative of the countries they took place in. Whilst they offer some valuable insights, and are presented here to generate further research and discussion, it is difficult to compare programmes that are based on different designs and applied in different contexts; and that given the particularity of the samples and the countries they were recruited in, it is not possible to generalise this evidence to the experiences of parents in low and lower-middle income countries worldwide. This new evidence provides hope that we can work towards a world free of violence against children. Parenting programs can play a crucial role in achieving SDG 16.2 and the contribution by Mejia et al considers the challenges that low and middle income countries currently face in ensuring the sustained implementation of parenting programs.

\section{What constitutes Violence against Children?}

Before the magnitude of the problem can be discussed it is necessary to provide a definition of what constitutes violence against children. Definitions of violence generally include any action that uses force, intended to cause harm. ${ }^{\mathrm{ii}}$ Thus, one needs to consider the meaning of the terms force, intention and harm. 'Force' can range from the use of firearms, to beating, slapping and 
shouting. How severe 'force' has to be in order to be included in this definition is unclear. Furthermore, it is not clear whether the threat of force constitutes violence. This broad definition also includes self-directed force. Determining 'intentionality' is also challenging. Asking perpetrators of violence about the intention may not yield honest or conclusive answers. Therefore, researchers often have to rely on inferring the intent through observation. 'Harm' is also a complex issue and can be understood as a moral and a legal concept. 'Harm' can include pain, death, disability, loss of ability or freedom, loss of pleasure (Gert, 2004) or can be defined as a setback to interests which includes fundamental rights such as the integrity and normal functioning of one's body (Feinberg, 1984).

Is there a globally agreed definition of what constitutes violence against children? The United Nations Convention on the Rights of the Child of 1989 sets out legally binding standards for the civil, political, economic, social, health and cultural rights of children and all UN member states (apart from the United States) have ratified this convention ${ }^{\text {iii }}$. Thus, there is a strong global consensus to protect children and safeguard their development and wellbeing. The convention acknowledges the rights and duty of parents but also obliges the signatories to take appropriate measures to protect children from all forms of physical violence, while in the care of parents or other caretakers (Article 19). All form of violence includes physical punishment that many parents use in the upbringing of their children. Physical punishment is also referred to as corporal punishment and I use the two expressions interchangeably. Some argue that any corporal punishment constitutes child abuse and that in order to reduce violence against children, physical punishment should be outlawed (see discussion in Freeman and Saunders 2014). However, globally only 52 countries do not allow any form of physical punishment by parents or any other adult. ${ }^{\text {iv }}$ Thus, although the UN convention requests that signatories take appropriate action against (parental) violence, only about one quarter of all countries have laws against corporal punishment. It has been argued that the UN convention is based on Western values and does not reflect the beliefs and practices in the Global South. ${ }^{v}$ For example the African Charter on the Rights and Welfare of the Child allows the administration of domestic discipline although it stipulates that 'this must be applied with humanity and be consistent with the inherent dignity of the child' (Article 20 (1c)). ${ }^{\text {vi }}$ Thus, in an African context there seems to be no fundamental contradiction between a child's dignity and physical punishment. This example suggests that violence against children is a social construct and underscores that currently there is no globally accepted definition. An additional reason why there is no such global definition is that cultural notions of childhood are diverse. The literature on childhood 
studies analyses the multiple concepts of 'childhood' and shows that the understanding of childhood is influenced by age, gender, ethnicity, history and location (Scheper-Hughes and Sargent 1998, Qvortrup et al 2009). This is in contrast to the UN convention where children are defined as any person under 18 years and are given universal rights.

The emphasis on parental violence is important because parents are the main perpetrators of violence against children (Pinheiro 2006). Unfortunately, there are no reliable global data but country specific statistics provide strong evidence for this claim. Take the United States as an example. In 2015 there were 1,650 child homicides in the United States and in 78 per cent of all of these cases at least one parent was the perpetrator. For the non-fatal abuse cases parents were also identified as the main perpetrators, 92 per cent of all cases involved at least one parent. ${ }^{\text {vii }}$ Parental violence is the first form of violence that most people experience in their lives, it is therefore the 'primordial' violence (Straus et al 2014). These early experiences of violence shape individuals' wellbeing, attitudes, behaviours and outcomes. Parental violence thus constitutes a considerable public health challenge (Sara and Lappin 2017) as well as a development challenge because parental violence reduces human capital, increases violence and delinquency (e.g. Webb et al 2017), substance abuse (e.g. Scheidell et al 2017) and risky sexual behaviour (e.g. Wamoyi et al 2015).

\section{Global Prevalence}

I now turn to the question how common the problem of parental violence is. Little is known about the global prevalence of violence against children. This is due to the difference in definition across societies but also because violence against children is massively underreported. This section discusses the existing evidence of fatal and non-fatal violence against children.

\section{Fatal Violence}

The World Health Organization (WHO) estimates that about 30,800 children died due to interpersonal violence in 2015. This estimate includes children aged zero to 14 where the cause of death was an assault or neglect (data on child homicide, in particular newborn homicide, are difficult to collect). These deaths are the killing of one person by another and I also refer to 
them as homicides. Note that the age definition of 'children' is not equivalent to the UN definition of under 18 years; unfortunately other WHO statistics are not available.

If no signs of physical violence are present, is it difficult to attribute the death to neglect rather than illness. For most countries detailed studies of child homicides are not available and the numbers should therefore be understood as approximations rather than precise estimates. ${ }^{\text {viii }}$ The number of violent child deaths as presented by the WHO may appear low, but international and national statistics of child homicides suggest that such killings are rare: Worldwide only seven per cent of all victims of fatal interpersonal violence are children. ${ }^{i x}$ The only other source that provides comparable data on interpersonal violence is the United Nations Office of Drugs and Crime (UNDOC). Their total homicide numbers are lower than the WHO data series and UNODC do not provide the age of the victim. Thus, for the purpose of assessing the magnitude of fatal violence against children the WHO provides the best worldwide data source.

At which age are children most at risk of homicide? To examine this question I compare the homicide rates per 100,000 of the relevant population. Using the WHO data for 2015, the global homicide rate is about 1.6 per 100,000 children aged zero to 14 . At first glance this appears to be a relatively low rate because the global homicide rate for persons older than 14 years is 8.1 per 100,000. However, when looking at specific age groups in Figure 1 it is striking that newborns (under one month) are at a much higher risk of homicide: the homicide rate for newborns is 23.7 per 100,000 . This is much higher than for older children and considerably higher than the rate at which the WHO considers homicides to be at an epidemic level (this threshold is 10 per 100,000$)$. 


\section{Figure 1: Global Child Homicides by Age}

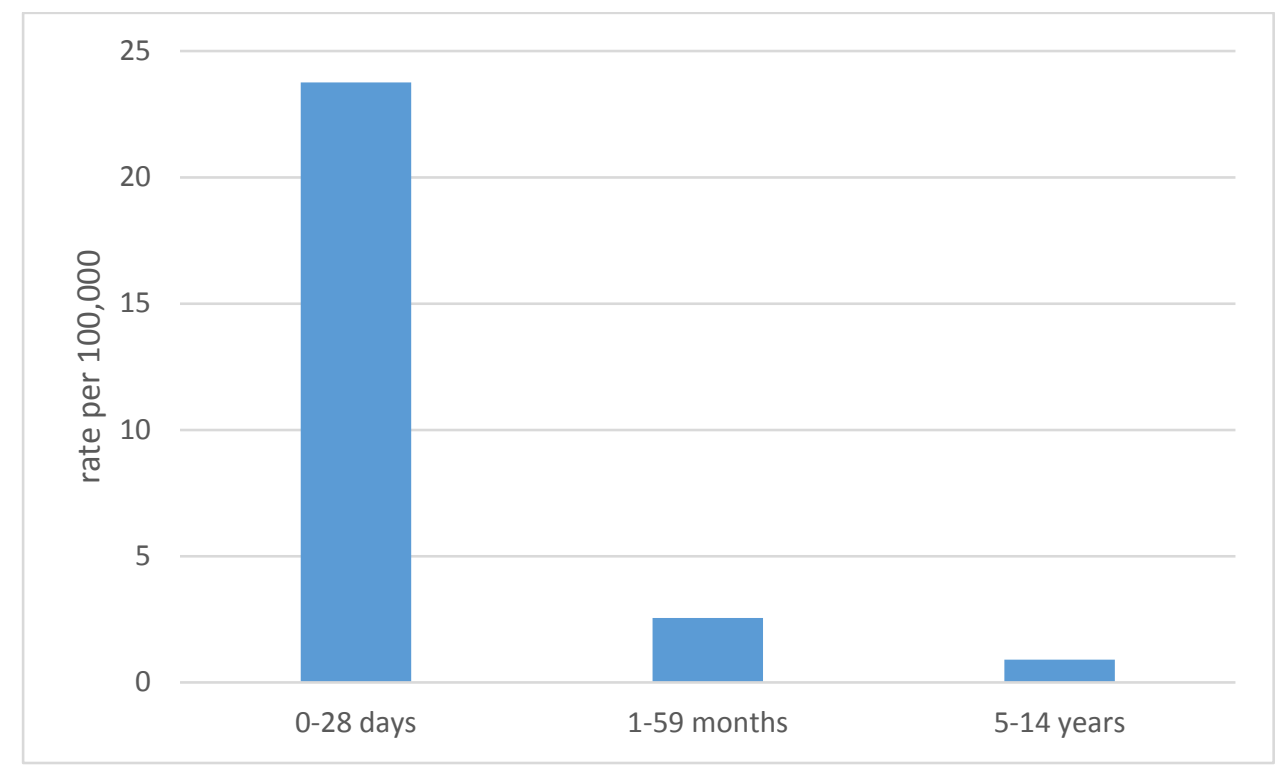

Source: WHO Global Health Estimates (GHE) 2015, own calculations.

A more detailed look at the newborn homicide rates suggests that they are highest for lower middle income countries (32 per 100,000) followed by low income countries $(25$ per 100,000). For high income countries rates are just under 5. A first inspection does not show much evidence of a gender dimension, globally the homicide rates for boys are 24 and for girls 23 per 100,000. A closer inspection of the regional data shows that all but two regions have higher homicide rates for newborn boys than for girls. The exceptions are South Asia and East Asia and Pacific. In South Asia homicide rates for newborn girls are 32 and for boys 23 per 100,000. Here I only highlight the gender differences and refer the interested reader to the literature on the causes, consequences and trends of the "missing girls and women" in China, India and Korea (Bhaskar and Gupta, 2007; Das Gupta et al 2009; Doo-Sub 2004; Ebenstein, 2010; Ebenstein and Sharygin, 2009).

The WHO data do not provide information on the perpetrator of these killings but since most victims are very young, the overwhelming majority of children are likely to be killed by their parents. The WHO also provides data on collective violence (armed conflict, terrorism). The number of child homicide victims is three times larger than those killed by collective violence. This gives an indication of the scale of the problem of parental violence against children. There is also a clear pattern in the homicide rates according to country income groups: children in low income countries are at much higher risk of becoming a victim of homicide. This risk is 
much higher for newborns than for older children. National income is not generally correlated with a higher risk for girls becoming victims of homicides, but cultural issues are important. In some Asian societies homicide rates for newborn girls are much higher than for boys.

\section{Non-fatal Violence}

There is no WHO databank offering comparable information on non-fatal child abuse. This is partly due to the difference in definition of violence against children across societies but also due to the fact that child abuse is massively underreported. In many cases the victims never report the abuse. This may be for a number of reasons, for example because they are too young to report the violence, they have a limited understanding what constitutes abuse and neglect, they feel ashamed and they think nobody will believe them. Many perpetrators are able to use their power to intimidate their victims into keeping silent about the abuse, alternative care situations are difficult or impossible to arrange, thus children feel they have to put up with their violent environment. So even if states collect official statistics they will be unreliable due to these low disclosure rates. Many countries, especially those with low incomes, do not keep records on child abuse and neglect because child protection services are unavailable or the legal systems are dysfunctional (Marcus 2014).

A relatively comprehensive data collection effort is based on the UN's Multiple Indicator Cluster Surveys (MICS). These surveys are used in a number of UNICEF reports (e.g. UNICEF 2010, 2014) and in academic studies (e.g. Akmatov 2011). In these MICS surveys primary care givers (in most cases these are the children's mothers) were asked about their child disciplinary practices at home, whereby discipline was assessed according to the Parent-Child Conflict Tactics Scale (see Straus et al 1989). Primary caregivers of two to 14-year olds were asked whether they, or any other member in the household, had used one of the following disciplining methods during past month:

- Non-violent discipline (e.g. gave him/her something else to do, explaining why behaviour was wrong, taking away privileges)

- Psychological aggression (e.g. shouted at him/her, called him/her dumb or lazy)

- Physical punishment (e.g. shook him/her, spanked, hit with bare hand on the bottom or other parts of the body, hit with a belt, stick or other hard object on the bottom/other parts of the body) 
- Severe physical punishment (e.g. hit or slapped him/her on the face, head or ears, beat him/her with an implement repeatedly)

There are comparable surveys from 68 countries. As discussed in the previous section there is no universal definition of what constitutes (parental) violence against children. What is regarded as excessive punishment and thus unacceptable discipline of children varies across societies. For the purposes of this editorial I define violence against children as severe physical punishment (see above) and exclude less severe physical punishment and psychological aggression from the analysis. This is a pragmatic solution because many parents slap or spank their children and do not consider this abusive (Straus et al 2014). Psychological aggression, although damaging to children, is also excluded because it is difficult to find a common definition and it is difficult to compare to physical aggression. Severe physical punishment, such as repeated beating with a belt or cane, is more likely to be recognised across the world as abusive towards children. Even in societies where corporal punishment is the norm, there are parameters that distinguish acceptable and unacceptable forms of adult physical aggression towards a child. Furthermore, there is a close link between severe physical punishment and abuse. Abusive parents also often use overly harsh discipline that is inappropriate for the child's age or misdemeanour and often this escalates when this corporal punishment fails to modify the child's behaviour. Parents then increase the violence by using corporal punishment more frequently or even more harshly (Whipple and Richey, 1997).

Even when concentrating only on the most severe form of corporal punishment as reported in the MICS, I estimate that the global prevalence rate is a staggering 17.5 per cent (for more discussion of the estimation methodology see Hoeffler 2017). In absolute numbers this means that about 311 million children are subjected to this violence every month. There is a strong indication that parents in low income countries use more violence to discipline their children than parents in high income countries. Figure 2 presents a scatter plot showing the relationship between country income and the percentage of primary care givers who used severe physical punishment. 


\section{Figure 2: Average Country Income and Severe Child Punishment}

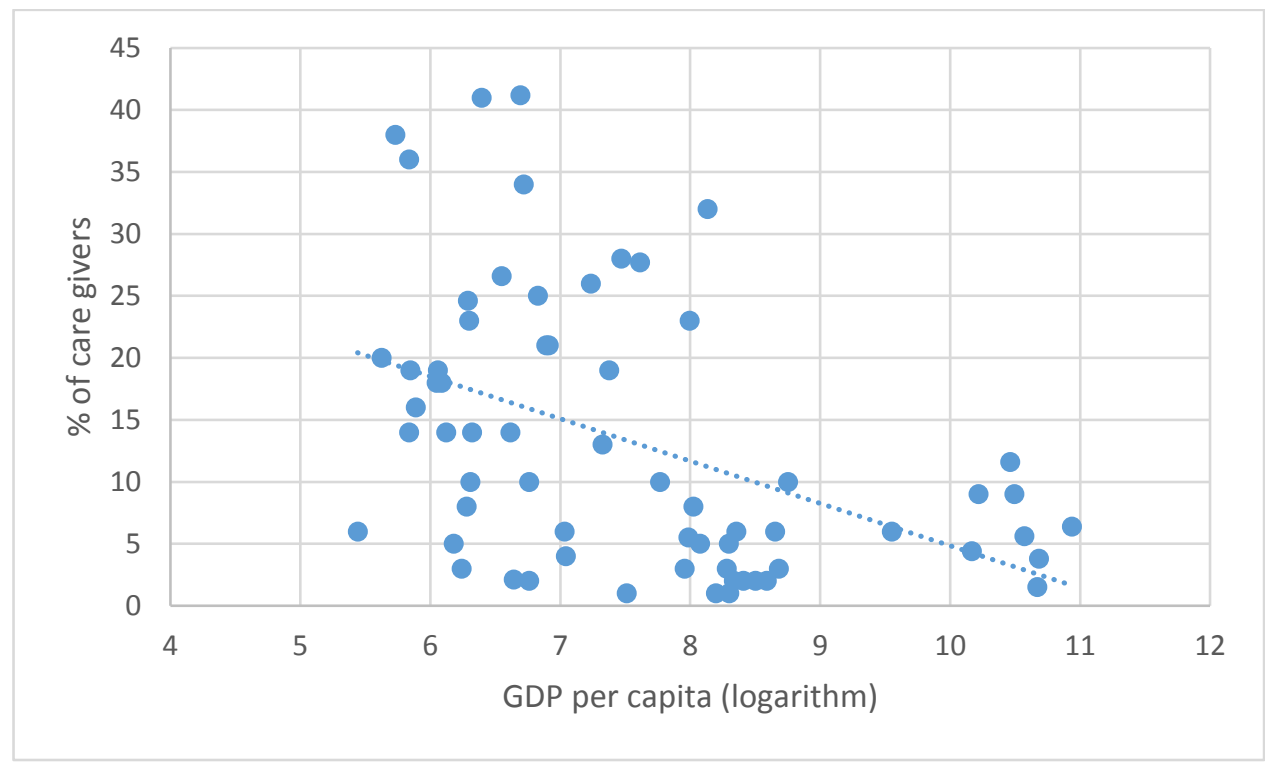

Note: The vertical axis shows the percentage of primary care givers who reported using severe physical punishment. Source: World Development Indicators, MICS and other child discipline surveys.

Even though there is a negative relationship between income and severe parental discipline, there are considerable variations at given incomes. The countries with the highest physical punishment rates are Yemen, Chad, Afghanistan and the Democratic Republic of the Congo. In these countries about 40 per cent of caregivers state that they used severe disciplining methods. These are all low income countries, but so are Zimbabwe, Malawi, Mali and Nepal countries where only 14 per cent or fewer stated that they used such severe punishment. Comparing upper middle income countries also shows considerable variation. About 20 per cent of all parents state that they have used severe punishment in Iraq, Algeria and Georgia, while three per cent or fewer parents did so in Cuba, Panama and Kazakhstan. This suggests that although income is negatively associated with violence against children, local norms are important. There are many factors that influence these norms, for example the experience of collective violence may increase family violence, including violence against children (Saile $e t$ al 2015).

Averaging by income groups in Figure 3 shows that severe punishment is about three times more prevalent in low income countries (23.2 per cent) when compared to high income countries (6.6 per cent). However, there is also considerable variation between countries, as discussed earlier. 


\section{Figure 3: Prevalence of Severe Child Punishment by Income Group}

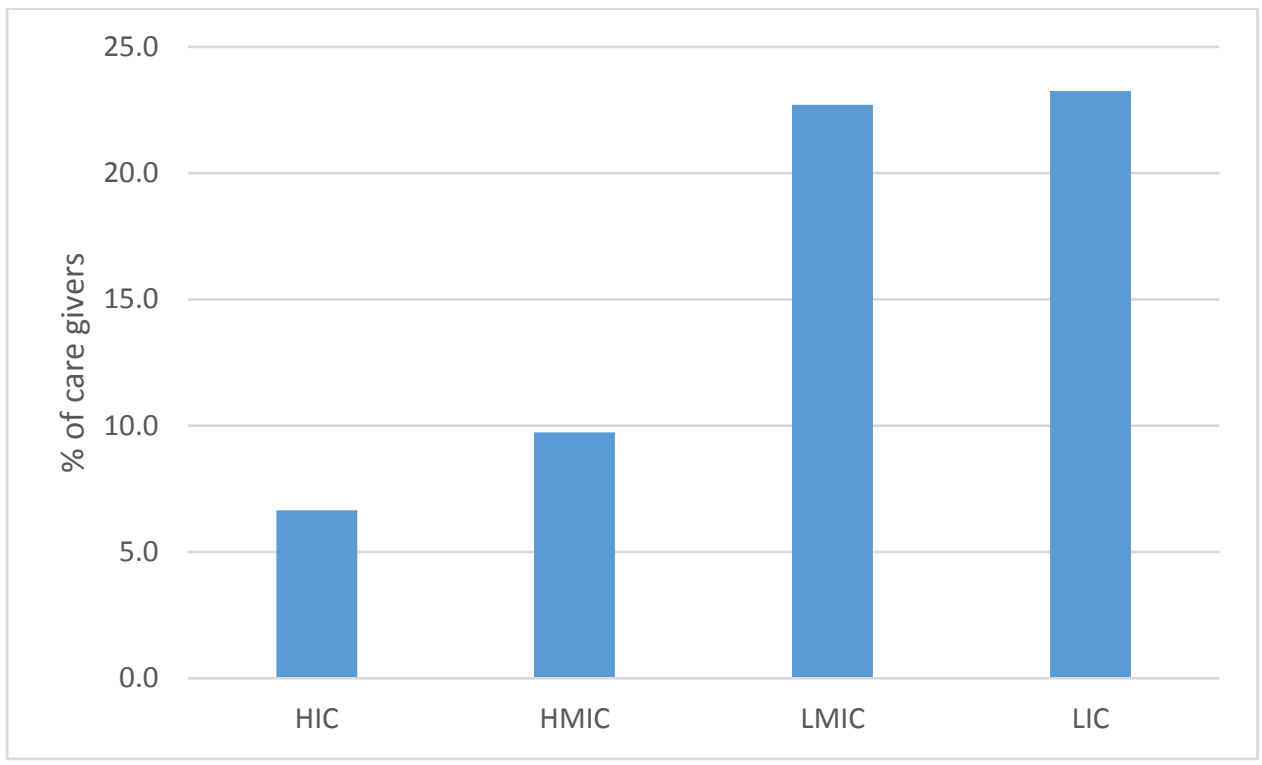

Notes: HIC - high income countries, UMIC - upper middle income countries, LMIC - lower middle income countries, LIC - low income countries. Source: MICS and comparable child discipline surveys.

Although the MICS provide a lot of detailed information on parental discipline methods and parental attitudes, this data collection effort also has a number of shortcomings. Here I only want to highlight the issue of self-reporting. There is no objective measure of whether the caregivers' answers are truthful. In societies where physical punishment of children is the norm, parents may overstate the use of these methods while parents in societies where physical punishment is not the norm may under-report their use of corporal punishment.

\section{Consequences of Parental Violence}

There is a large literature on the consequences of child maltreatment. As the discussion above suggests, much of this maltreatment is harsh parenting, including physical punishment. The research shows that child maltreatment substantially contributes to child mortality and morbidity, has long lasting effects on mental health, school achievement, substance abuse, risky sexual behaviour, obesity and criminal behaviour, which persist into adulthood (e.g. Fang et al 2012\& 2015; Dube et al 2003; Hecker et al 2016; Nemeroff 2004\&2016; Norman et al 2012). ${ }^{\mathrm{x}}$ Presumably, parents use violence without being aware of these unintended consequences. It is therefore useful to reflect on why parents use corporal punishment. Typically physical punishment involves delivering pain, but not lasting pain or injury on the 
child (Gershoff 2010), aiming to modify children's behaviour. In the short run parents want to stop their child from engaging in unwanted behaviour and to achieve compliance. They may also want to get their child's attention or let the child know that the parent is in charge. In the longer term they want to prevent their child from repeating this unwanted behaviour and increase the likelihood that they behave in a socially acceptable way. ${ }^{x i}$ In addition to using physical aggression to educate the child, the use of physical force may also be the release of frustration and anger (for further discussion on the motives see Straus et al 2014's review of different studies in the US). Physical punishment does not only result in children experiencing pain; they also feel humiliated, helpless and upset, especially if they felt the punishment was unjust (on punishment from the child's perspective see Twum-Danso 2013). Children who receive corporal punishment have measurably higher stress levels, using saliva and blood tests Hecker et al (2016) find increased cortisol levels in a sample of Tanzanian children.

One important issue is how reliable the evidence on the consequences of violence against children is. The evidence of the unintended consequences of violence is mainly based on crosssectional studies, e.g. a comparison of different countries or regions/states within countries. For these types of studies the association between corporal punishment and social outcomes should not necessarily be interpreted as causal. The association between corporal punishment and negative outcomes may be endogenous. There may be reverse causality (e.g. low school achievement may make parents more aggressive) or the association may be determined by a third variable that determines corporal punishment as well as the negative outcome (e.g. low income drives violent behaviour as well as poor health outcomes).

Stronger causal evidence emerges from longitudinal studies. These studies follow children over a long period of time and such data analysis provides a better framework for the examination of causality because it enables researcher to compare the effect of corporal punishment on individuals' outcomes (e.g. income, academic achievement, criminal activity) while controlling for their childhood environment such as whether they were living with their birth parents, the number of siblings and their parents' age, education and income. The link between crime and violence experienced in childhood is examined by Straus et al (1997). ${ }^{\text {ii }}$ Parents in the United States were asked whether they used corporal punishment when their children were between eight and 14 years old. In their follow up study they surveyed these children when they were young adults aged between 18 and 23. Controlling for ethnicity, income, parents' education and a number of other factors, young men were significantly more likely to engage 
in criminal behaviour if they were hit by their parents in the past. A similar approach was taken by Webb et al (2017) in their study of the impact of childhood trauma in Denmark. Violencerelated hospital admissions during childhood were associated with higher rates of self-harm in young adult women and criminal behaviour in young adult men. Another example is the longitudinal study in the US by Scheidell et al (2017) showing that physical abuse in childhood substantially increased the likelihood of adolescent and adult use of marijuana and cocaine. These examples are all longitudinal studies from high income countries, to my knowledge there are no such studies on the impact of violence in the home on adult outcomes from low income countries.

Randomized Controlled Trials (RCTs) are standard in medical science and have become very popular in social science because the comparison of control and treatment groups allows researchers to establish a causal link between treatment and outcome (for a criticism of RCTs in social science see Deaton 2010). The use of RCTs in the study of violence is problematic, mainly because for ethical reasons parents should not be randomly assigned to using corporal punishment. Hence, very few studies have used RCTs. A notable exception is the work by Roberts and colleagues (Day and Roberts, 1983; Roberts 1988; Roberts and Powers, 1990). They randomly assigned one group of caregivers to hit their child when it left 'time out' and the other group to use non-violent tactics, such as just putting their child back into 'time out' ' xii The results from these studies suggest that there is no difference in the effectiveness of the two disciplining methods.

In summary, there is there is evidence of a relationship between abuse and neglect and negative outcomes for children, although as this evidence is from cross-sectional studies the relationship may not be causal. Much of the detrimental effect of corporal punishment is attributed to the decrease in parental attachment. Children who are hit by their parents feel less secure in their attachment at a young age (Coyl et al 2002) and as adolescents (Palmer and Hollin 2001). Children who feel less secure are more likely to internalize problems resulting in mental health problems and self-harm or externalize them through aggression and violence.

While this discussion of the consequences is far from comprehensive, the evidence presented suggests that not only abuse and neglect but also widely accepted forms of parental violence can have a considerable impact on children's wellbeing and their future development. In the aggregate human capital and earnings potential will be lower, societies will have higher rates 
of anti-social behaviour, more (violent) crime, higher prevalence of intimate partner violence and future corporal punishment. There are also considerable health consequences due to higher rates of depression, anxiety and higher rates of risky sexual behaviour (STDs, unwanted pregnancies, abortions). Evidence is largely based on high income countries, highlighting the need to gain more insights from middle- and low income countries.

\section{Strategies to Reduce Parental Violence}

The serious and long-term consequences of child maltreatment warrant an increased investment in preventive strategies from early childhood. This section starts with a brief overview of what is known about why and when parents use corporal punishment, before moving on to discuss which strategies can be used to reduce violence.

The use of corporal punishment in the United States is well documented (Straus and Stewart 1999; Straus et al 2014: chapter 1). Children aged five or under are most likely to be physically punished by their parents and 80 per cent of all parents had hit their two year old child during the past year. The rate of using any type of physical punishment peaks for four and five year olds (93 per cent) and then steadily declines until they are 17 years old. Parents who hit their children do it frequently and the risk of child abuse is much higher for parents who hit their children (Ibid). The severity of the punishment depends on the age of the child, young children are slapped or spanked while older children receive more severe forms of physical punishment, such as being hit with a belt, paddle or hairbrush. In the United States parents are more likely to use corporal punishment if they are young, have low socio-economic status or have a substance abuse problem and they are more likely to hit boys than girls (Ibid). Recent qualitative evidence from Vietnam, Peru, Ethiopia and India also suggests a clear gender dimension, boys are more often subjected to physical punishment than girls (Vu 2016; Guerrero and Rojas 2016; Pankhurst et al 2016; Morrow and Singh 2016).

Using the MICS evidence Akmatov (2010) suggests that the risk factors of corporal punishment are similar in low and middle income countries: Parents mainly use less severe forms of physical violence against two to five year olds and more severe forms against older children. However, the frequency of corporal punishment decreases with the child's age. Income is also 
important, poorer parents hit their children more often. Children in larger households also experience more violence and cultural differences matter: in Sub-Saharan Africa corporal punishment is more prevalent than in other world regions (Akmatov 2010; Hoeffler 2017).

The study by Boydell et al in this issue also shows that Ugandan mothers frequently use physical punishment for their very young children (18-36 months). All of this evidence on hitting toddlers suggests that many caregivers may have unrealistic expectations of children's developmental and behavioural capabilities (Sanders 2012). Children under the age of three are typically not capable of consistently following simple instructions (Department of Health, 2009).

The evidence from MICS and comparable surveys suggests that parental violence against children is strongly linked with poverty; the prevalence of corporal punishment is higher in low income countries and within countries children in poorer households children are at a higher risk. Economic development is thus of great importance if we want to move towards a world free of violence against children. However, while poverty, age of the child, age of the parent and sex of the child have a significant impact on the risk of corporal punishment, this relationship is not deterministic. Poor caregivers are more likely to hit their children, but not all do so. Cultural norms moderate attitudes towards violence and set boundaries for acceptable behaviour. The cultural attitudes towards corporal punishment vary widely across societies (Lansford et al 2005) and they are correlated with other forms of violence, for example boys fighting physically (Straus et al 2014: chapter 5), and 'wife beating' (Fluke et al 2010).

Cultural norms change over time and it is instructive to consider how some societies have developed a consensus that physical punishment of children is unacceptable. The first country to outlaw "physical punishment and other injurious or humiliating treatment" was Sweden in 1979. Another 51 countries have followed suit. Broadly speaking the first countries to follow the Swedish example were the other Nordic states, Austria and Germany. The movement then spread to other high income countries and some middle and low income countries, e.g. Uruguay, Kenya, Turkmenistan. There is of course a gap between the aspiration and reality, some children are hit, even in Sweden, but cross-national evidence shows that Swedish students report the lowest rate of parental violence when compared to 18 other countries (Douglas and Straus 2006). However, outlawing all violence against children may not deliver the desired result, because when legal norms run counter to social norms, legislative reform has a limited 
effect on changing attitudes and practices (Platteau and Wahhaj 2014; UNICEF 2013:89). The article by Van Esch and De Haan on Western Kenya in this special issue suggests that this may be the case for Kenya. Although corporal punishment has been outlawed, it seems to run counter to social norms where parents frequently use corporal punishment. A more successful strategy may be to first outlaw certain types of violence against children, such as by teachers or other adults in authority, and then extend legislation to cover parental violence. ${ }^{\text {xiv }}$ While parents in most countries have the right to use physical punishment, many do not allow corporal punishment of children by others. For example in the United States it is lawful in all states for parents to inflict physical punishment on their children but this punishment is only lawful in public and private schools in 19 states. $^{\mathrm{xv}}$ In Sweden corporal punishment was first banned in secondary schools in 1928 (these secondary schools were selective and only a small proportion of the population, typically from the upper middle class, went to these). Corporal punishment in all schools was banned in 1960, followed by general abolition, including in the home (for more detail see Durrant, 1996).

Thus, one way of enabling social change is through the law. The aim of legal reform is not only to limit the use of harmful traditional practices but also to change attitudes and thus prevent violence. Legal reform can reduce previously culturally acceptable violence but this is only possible if legal norms are not in total contrast to prevailing social norms. Changing norms can take time and in the short term interventions aimed at changing individuals' behaviour are easier to achieve, especially if they are 'culturally compelling' (Panter-Brick et al 2006). These individual behaviour changes will in the aggregate influence community norms. Parenting programs are a way to bring these changes about, as they are designed to improve the child parent bond and use nonviolent disciplining methods. Developed by psychologists these parenting programs have their origins in social learning theory ${ }^{\mathrm{xvi}}$, where it is assumed that learning is a cognitive process that takes place in a social context, such as the family home. Direct reinforcement is not necessary for learning to occur, learning can happen purely through observation or instruction. The aim is to equip parents with skills and knowledge about raising children. The focus of the skills teaching is on praise and non-violent discipline methods, such as ignoring, taking privileges away or time out. This approach is also referred to as positive parenting and a number of programs have been developed. Examples include: The Incredible Years Parent Training (IYPT), Positive Parenting Program (Triple P) and Parenting for Lifelong Health (WHO and UNICEF initiative). The programs are designed to improve parenting and help with behavioural, emotional and developmental problems in children. An 
important aspect is for parents to develop realistic expectations and assumptions about their children's behaviour and choose goals that are developmentally appropriate for the child. The methods of delivering parenting advice range from general parenting information campaigns, to group teaching sessions and family interventions to help with specific problems. Parenting programs have been used in a number of countries and have been evaluated in a rigorous manner. The evaluations suggest that parenting programs can substantially reduce the maltreatment of children (Barlow et al 2006; Piquero et al 2008; Prinz et al 2009). Most of the evidence comes from high income countries; so far parenting programs have only been used in a few low income countries where corporal punishment is much more widespread. Parenting programs appear to be a feasible social policy intervention in many countries, because the majority of caregivers do not believe that physical punishment is necessary in disciplining their children (based on surveys in 33 low and middle income countries, see UNICEF 2010). Thus, this indicates that the majority of caregivers appear to be open to improving their parenting skills to avoid physical punishment. While there are only a few studies of parenting programs in low income countries, the evidence from middle income countries is encouraging. Based on their systematic review Knerr et al (2013) show that parenting programs are at least as effective when transported to countries different from where they originated. However, the majority of the reviewed studies were in middle income countries, there were only two studies from a lowincome country (Ethiopia). Knerr et al (2013) conclude that the transportability to societies with different norms is relatively unproblematic and extensive adaptation is unnecessary. However, despite these encouraging findings, the authors highlight the need for a better understanding of which parts of the program should be common in all settings and which parts should be adapted according to the local context and norms. This understanding would further improve the success of the interventions and provide an easier to copy template that could be scaled up in a cost-effective manner. This special issue contributes to this deeper understanding of local context by presenting qualitative evidence from Liberia, Kenya and Uganda.

Giusto et al consider a parenting intervention in rural Liberia which lead to a 55 per cent decrease of parent self-reported violence against children (Puffer et al 2015). This parenting intervention, Parents Make the Difference (PMD), consisted of 10 sessions for parents of children aged 3-7. Giusto et al examine the mechanisms behind the effects of this intervention. Like all parenting programs PMD is a multicomponent program covering positive parenting, childhood development, appropriate expectations, communication, empathy, routine, discipline and stress management. Using semi-structured interviews with 30 rural caregivers 
Giusto et al find that the information on the harmful effects of harsh punishment on child development and the value of empathy for children were important drivers of change, while the adoption of new behavioural skills seemed to be of secondary importance.

The study of a parenting intervention in Western Kenya by Van Esch and De Haan comes to somewhat different conclusions related to the role of behaviour change. They use semistructured interviews with 25 rural parenting programme participants to analyse the Skillful Parenting (SP) Program which has five elements: family relations, parental roles and responsibilities, self-care and self-esteem, values and discipline and communication. One of the outcomes of the program was less self-reported caning of children. The main driver appeared to have been the non-violent discipline methods which parents experienced as more effective in modifying behaviour than caning. A further important aspect raised by van Esch and de Haan is that the program was successful despite not working through the channel of more secure attachment. Parenting programs see insecure attachment as a deficit that needs to be addressed in order to improve child wellbeing. Much of the emphasis is on dedicated parent (mostly mother) to child interaction. In societies where much of the parenting is shared and parents direct their children without a lot of one-to-one interactions as in Western Kenya, the route to improving child outcomes may not be through focusing on improving attachment.

The issue of attachment is also highlighted in the contribution by Boydell et al. They examine the challenges faced by very poor and marginalised mothers in urban Uganda and how they bring up their children. The focus is on children aged 18-36 months. All of the mothers found managing their toddlers' behaviour difficult and used physical punishment and withholding of food to discipline them. The reasons mothers stated for this harsh discipline were largely to enforce socially acceptable behaviour, such as greeting others properly and not interrupting adults. Although the specific examples provided were different, these mothers' motivation to use corporal punishment, namely social respectability, was very similar to the one cited by US parents (Straus et al 2014). The children's behaviour in public is regarded as a direct reflection of the mother's respectability. Most mothers had no support from the fathers and struggled to pay for rent, food, health care and education. The mothers reported engaging in transactional sex, including commercial sex work, and this meant they had to leave their children in the care of others. As a consequence they spent little time with their children and the authors concluded that any parenting intervention has to recognise the limits extreme poverty places on the ability to practise positive parenting. 
The focus of the article by Siu et al is on the role of fathers. They analyse a pilot study of a Ugandan designed parenting program named 'Parenting for Respectability', reflecting the concerns of parents that they need to maintain the family's respectability. This is in large part achieved through the socially appropriate behaviour of their children. The participants live in Wakiso district, which includes rural and peri-urban settings, and were chosen from preexisting savings groups and fathers' and mothers' groups. Siu et al then conducted in depth, semi-structured interviews with 24 fathers. These men were representative of the fathers who attended the programme in terms of attendance record and whether their spouse attended. The intervention consisted of 21 sessions where mothers and fathers participated separately during the first 10 sessions. All of the male only sessions lasted longer than anticipated, reflecting a desire to explore the expectations and constraints of conventional masculinity. The men welcomed an intervention recognizing them as equal partners in the upbringing of their children and their concern for their children's wellbeing. In the semi-structured interviews many fathers reported a reduction of spousal conflicts and increase in mutual respect. This more peaceful relationship at home was regarded as a very positive outcome of the program. This was also remarked upon by parents in the Liberia study by Giusto et al. This more peaceful home environment should reduce physical violence between the parents, set a good example to the children and reduce stress for the adults as well as the children. The Siu et al pilot study suggests that it is important to involve fathers and possible to recruit and retain them if the intervention is aimed at topics that are of importance to them, in this case 'respectability'.

Given the efficacy of the parenting programs discussed in the four preceding papers, Meija et al discuss the challenges low and middle income countries face in the sustained implementation of parenting programs. First, governments have to make the protection of children a key priority. In order to achieve population level change programs should have universal reach. This requires the joint parallel efforts by different government agencies, such as educational, social, community and health services. Meija et al list six challenges that have to be tackled in order to achieve universal implementation. Here I highlight two. One is that there is currently low implementation capacity; there are few local experts. One solution is to train individuals to stay in touch with 'outside knowledge' who can then adapt and implement interventions for local needs. The sustainability of the programs could be ensured through an information cascade in which these pivotal individuals pass on their knowledge to train facilitators locally. Giusto et al found that some participating parents became strong advocates for the program and were keen to impart their knowledge. These can be trained as peer supporters to ensure the 
scaleability and sustainability of the program. A further challenge of implementation at large scale is that program quality and fidelity may be compromised. Commercialised western programs come with a quality assurance system but their high costs are typically prohibitive. Solutions include the development of local solutions but tailor-made approaches also tend to be expensive. Adaptation of existing programs are cheaper and could be overseen by not-forprofit organisations such as academic institutions or international agencies. Another way forward proposed by Meija et al are joint ventures with commercial parenting programs, possibly learning from the licencing agreements in the pharmaceutical industry. ${ }^{\text {xii }}$

\section{Conclusion}

Violence against children is a recognized human rights and public health issue but in this article I suggest that the topic should receive more attention in development research. There is considerable evidence that violence during childhood not only inflicts pain and suffering, but has also long lasting adverse consequences, not only for the individual, but for societal development. Most of this evidence comes from high income countries where violence against children is less prevalent. Without longitudinal studies from low income countries it is therefore currently not possible to establish whether the adverse societal problems due to childhood violence are similar in character and magnitude to those in high income countries. However, given the high prevalence rates in low income countries it is surprising how little attention and resources the issue of violence against children has received.

Most of the violence against children is committed by their parents (Pinheiro 2006) and this editorial provides an overview of the current knowledge. Many parents use physical punishment, also referred to as corporal punishment, in the upbringing of their children. Surveys provide data on the extent of the use of such violence. Mothers, or other primary care givers, report which disciplining tactics they have used in the past month. Responses that include hitting the child's head and using implements (e.g. belts, canes) repeatedly are recorded as severe physical punishment. This form of violence is highly prevalent; estimates suggest that about 311 million children are subjected to severe physical punishment each month, this is 17.5 per cent of all children globally. The prevalence rates of severe physical punishment is considerably higher in low income countries, here over 23 per cent of all children receive such punishment, compared with under 7 per cent in high income countries. This macro evidence suggests a causal link running from poverty to violence against children; this is also the case in 
some studies at the micro level, where children from poorer households are subjected to harsher discipline.

Since most of the violence is perpetrated by parents a starting point in the reduction of violence against children is to improve parenting knowledge and skills. Over the past two decades parenting programs have been developed and implemented with considerable success in high income countries, primarily through improving the child-parent bond and increasing the use of non-violent discipline methods. So far the evidence from low income countries is sparse and this special issue addresses this knowledge gap by providing evidence on parenting programs in very poor communities in Liberia, Western Kenya and Uganda. All of the parenting interventions are multicomponent programs and the qualitative evidence discussed in the articles provides further insights into which components are the strongest drivers in changing parental attitudes and behaviour. Disentangling the mechanisms behind change is of considerable importance in low income countries, because the knowledge of the important drivers would allow the design of shorter, light touch interventions. These are less costly to implement and would facilitate the sustainability and scaleability of parenting interventions. Although there is some evidence that parenting programs can be transferred to different cultural settings without a decrease in effectiveness (Knerr et al 2013), it is less clear how material constraints impact on the ability of parents to change their caregiving practices. Despite living in poverty, individuals can be encouraged to make positive behavioural changes (Banerjee and Duflo 2011). However, currently it is not clear how poverty impedes the effectiveness of parenting programs. The daily stressors in the form of hunger, disease, crowded living conditions as well as the impact of poverty on cognition (Mani et al 2013) could constitute considerable obstacles. This is an important avenue for future research. 


\section{References}

Akmatov M. 2011. Child abuse in 28 developing and transitional countries-results from the Multiple Indicator Cluster Surveys. Int J Epidemiol 40:219-27. doi:10.1093/ije/dyq168

Bandura, A. 1977. Social Learning Theory. Oxford, England: Prentice-Hall.

Banerjee, A.V. and Duflo, E., 2011. Poor Economics: Barefoot Hedge-fund Managers, DIY Doctors and the Surprising Truth about Life on Less Than 1 [dollar] a Day. Penguin Books.

Barlow, J., Johnston, I., Kendrick, D., Polnay, L. and Stewart-Brown, S., 2006. Individual and group-based parenting programmes for the treatment of physical child abuse and neglect. The Cochrane Library.

Bhaskar, V and B. Gupta. 2007. India's missing girls: biology, customs, and economic development. Oxford Review of Economic Policy 23(2): 221-238.

Coyl, D.D., Roggman, L.A. and Newland, L.A., 2002. Stress, maternal depression, and negative mother-infant interactions in relation to infant attachment. Infant Mental Health Journal, 23(1-2): 145-163.

Danese, A. and Baldwin, J.R., 2017. Hidden wounds? Inflammatory links between childhood trauma and psychopathology. Annual review of psychology 68: 517-544.

Das Gupta, M., W. Chung and L. Shuzhuo. 2009. Evidence for an Incipient Decline in Numbers of Missing Girls in China and India, Population and Development Review 35 (2): 401-416.

Day, D.E. and Roberts, M.W., 1983. An analysis of the physical punishment component of a parent training program. Journal of Abnormal Child Psychology, 11(1): 141-152.

Deaton, A. 2010. Instruments, Randomization, and Learning about Development. Journal of Economic Literature 48 (2): 424-455.

Department of Health, 2009. Birth to five.

http://www.publichealth.hscni.net/publications/birth-five

Doo-Sub, K. 2004, Missing Girls in South Korea: Trends, Levels and Regional Variations, Population 59(6): 865-878.

Douglas, E.M. and M.A. Straus. 2006. Assault and injury of dating partners by university students in 19 countries and its relation to corporal punishment experienced as a child. European Journal of Criminology, 3: 293-318.

Dube, S.R., Felitti, V.J., Dong, M., Chapman, D.P., Giles, W.H. and Anda, R.F., 2003. Childhood abuse, neglect, and household dysfunction and the risk of illicit drug use: the adverse childhood experiences study. Pediatrics, 111(3): 564-572.

Durrant, Joan E. 1996. The Swedish Ban on Corporal Punishment: Its History and Effects. In: Family Violence Against Children: A Challenge for Society, Walter de Gruyter \& Co., Berlin, New York, 1996. (pp.19-25)

Durrant, J.E. and Smith, A.B. eds., 2010. Global pathways to abolishing physical punishment: Realizing children's rights. Routledge. 
Ebenstein, A. Y. 2010. The "Missing Girls" of China and the Unintended Consequences of the One Child Policy. Journal of Human Resources 45 (1): 87-115.

Ebenstein, A. Y. and Sharygin, E.J. 2009. The Consequences of the "Missing Girls" of China. World Bank Economic Review 23 (3): 399-425.

Fang, X., Fry, D.A., Brown, D.S., Mercy, J.A., Dunne, M.P., Butchart, A.R., Corso, P.S., Maynzyuk, K., Dzhygyr, Y., Chen, Y. and McCoy, A., 2015. The burden of child maltreatment in the East Asia and Pacific region. Child abuse \& neglect, 42, pp.146-162.

Fang, X., Brown, D. S., Florence, C. S., \& Mercy, J. A. (2012). The economic burden of child maltreatment in the United States and implications for prevention. Child Abuse \& Neglect, 36, 156-165.

Fearon, J. and A. Hoeffler. 2014. Benefits and Costs of the Conflict and Violence Targets for the Post-2015 Development Agenda. Copenhagen Consensus Center.

Feinberg, Joel. 1984. The Moral Limits of the Criminal Law, Volume 1: Harm to Others. New York: Oxford University Press.

Fluke, J., Casillas, C., Capa, C., Chen, L. and Wulczyn, F., 2010. The Multiple Indicator Cluster Survey (MICS) of households: Cross-national surveillance system to address disciplinary practices. In International Family Violence and Child Victimization Research Conference Portsmouth, NH.

Freeman, M. and Saunders, B.J., 2014. Can we Conquer Child Abuse if we don't Outlaw Physical Chastisement of Children?. The International Journal of Children's Rights, 22(4), pp.681-709.

Gershoff, E.T., 2002. Corporal punishment by parents and associated child behaviors and experiences: a meta-analytic and theoretical review. Psychological bulletin, 128(4), p.539.

Gershoff, E.T., 2010. More harm than good: A summary of scientific research on the intended and unintended effects of corporal punishment on children. Law and Contemporary Problems, 73(2): 31-56.

Gert, Bernard. 2004. Common Morality, Oxford University Press.

Gilbert, R., Widom, C.S., Browne, K., Fergusson, D., Webb, E. and Janson, S., 2009. Burden and consequences of child maltreatment in high-income countries. The lancet, 373(9657), pp.68-81.

Grusec, J.E. and Goodnow, J.J., 1994. Impact of parental discipline methods on the child's internalization of values: A reconceptualization of current points of view. Developmental psychology, 30(1): 4.

Guerrero, G. and V. Rojas (2016). Understanding Children's Experiences of Violence in Peru: Evidence from Young Lives, Innocenti Working Paper 2016-17, UNICEF Office of Research, Florence. 
Hecker, T., Hermenau, K., Salmen, C., Teicher, M. and Elbert, T., 2016. Harsh discipline relates to internalizing problems and cognitive functioning: findings from a cross-sectional study with school children in Tanzania. BMC psychiatry, 16(1), p.118.

Hecker, T., Radtke, K.M., Hermenau, K., Papassotiropoulos, A. and Elbert, T., 2016. Associations among child abuse, mental health, and epigenetic modifications in the proopiomelanocortin gene (POMC): a study with children in Tanzania. Development and psychopathology, 28(4pt2), pp.1401-1412.

Hermenau, K., Hecker, T., Elbert, T. and Ruf-Leuschner, M., 2014. Maltreatment and mental health in institutional care - Comparing early and late institutionalized children in Tanzania. Infant mental health journal, 35(2), pp.102-110.

Hoeffler, A. 2017. What are the Costs of Violence? Politics, Philosophy \& Economics. Accepted.

Jenks, Chris. 2005. Childhood. 2nd ed. Routledge: Abingdon and New York.

Kadushin, A. and J.A. Martin. 1981. Child abuse: an interactional event. Columbia University Press: New York.

Knerr, W., Gardner, F. and Cluver, L., 2013. Improving positive parenting skills and reducing harsh and abusive parenting in low-and middle-income countries: A systematic review. Prevention Science, 14(4), pp.352-363.

Lansford, J.E., Chang, L., Dodge, K.A., Malone, P.S., Oburu, P., Palmérus, K., Bacchini, D., Pastorelli, C., Bombi, A.S., Zelli, A. and Tapanya, S., 2005. Physical discipline and children's adjustment: Cultural normativeness as a moderator. Child development, 76(6): 1234-1246.

Mani, A., Mullainathan, S., Shafir, E. and Zhao, J., 2013. Poverty impedes cognitive function. Science, 341(6149): 976-980.

Marcus, R. 2014. Child protection violations and poverty in low-and middle-income countries. Background Note. ODI: London. https://www.odi.org/sites/odi.org.uk/files/odiassets/publications-opinion-files/9303.pdf, accessed 21 August 2017.

Mathews, S, N. Abrahams, R. Jewkes, L. J. Martin and C. Lombard. 2013. The epidemiology of child homicides in South Africa. Bull World Health Organization 91:562-568.

Molnar, B.E., Buka, S.L., Brennan, R.T., Holton, J.K. and Earls, F., 2003. A multilevel study of neighborhoods and parent-to-child physical aggression: Results from the project on human development in Chicago neighborhoods. Child maltreatment, 8(2): 84-97.

Morrow, V. and R. Singh. 2016. Understanding Children's Experiences of Violence in Andhra Pradesh and Telegana, India: Evidence from Young Lives, Innocenti Working Paper 2016-19, UNICEF Office of Research, Florence.

Nemeroff, C.B., 2004. Neurobiological consequences of childhood trauma. The Journal of clinical psychiatry 65:18-28.

Nemeroff, C.B., 2016. Paradise lost: the neurobiological and clinical consequences of child abuse and neglect. Neuron, 89(5), pp.892-909. 
Norman, R.E., Byambaa, M., De, R., Butchart, A., Scott, J. and Vos, T., 2012. The long-term health consequences of child physical abuse, emotional abuse, and neglect: a systematic review and meta-analysis. PLoS Med, 9(11), p.e1001349.

Palmer, E.J. and Hollin, C.R., 2001. Sociomoral reasoning, perceptions of parenting and selfreported delinquency in adolescents. Applied cognitive psychology, 15(1): 85-100.

Pankhurst, A. N. Negussie and E. Mulugeta (2016). Understanding Children's Experiences of Violence in Ethiopia: Evidence from Young Lives, Innocenti Working Paper 2016-25, UNICEF Office of Research, Florence.

Panter-Brick, C., Clarke, S.E., Lomas, H., Pinder, M. and Lindsay, S.W., 2006. Culturally compelling strategies for behaviour change: a social ecology model and case study in malaria prevention. Social science \& medicine, 62(11), pp.2810-2825.

Pereznieto, P, Montes, A, Routier, S and L Langston. 2014. The costs and economic impact of violence against children. Research reports and studies. ODI, London.

http://www.odi.org/sites/odi.org.uk/files/odi-assets/publications-opinion-files/9177.pdf

Platteau, J.P., and Z. Wahhaj. 2014. Strategic Interactions Between Modern Law and Custom. In: V. Ginsburgh and D. Throsby (Eds.), Handbook of the Economics of Art and Culture, Vol. 2, Elsevier and North-Holland, pp. 633-678.

Pinheiro, PS. 2006. World Report on Violence Against Children. WHO. Geneva.

Piquero, A.R., Farrington, D.P., Welsh, B.C., Tremblay, R. and Jennings, W.G., 2009. Effects of early family/parent training programs on antisocial behavior and delinquency. Journal of Experimental Criminology, 5(2), pp.83-120.

Prinz, R.J., Sanders, M.R., Shapiro, C.J., Whitaker, D.J. and Lutzker, J.R., 2009. Populationbased prevention of child maltreatment: The US Triple $\mathrm{P}$ system population trial. Prevention Science, 10(1): 1-12.

Puffer, E.S., Green, E.P., Chase, R.M., Sim, A.L., Zayzay, J., Friis, E., Garcia-Rolland, E. and Boone, L., 2015. Parents make the difference: a randomized-controlled trial of a parenting intervention in Liberia. Global Mental Health, 2. Open Access.

Renteln, A.D., 2013. International human rights: universalism versus relativism. Quid Pro Books: New Orleans.

Roberts, M.W., 1988. Enforcing chair timeouts with room timeouts. Behavior Modification, 12(3): 353-370.

Roberts, M.W. and Powers, S.W., 1990. Adjusting chair timeout enforcement procedures for oppositional children. Behavior Therapy, 21(3): 257-271.

Qvortrup, J., Corsaro, W.A., Honig, M.S. and Valentine, G. eds., 2009. The Palgrave handbook of childhood studies. Basingstoke: Palgrave Macmillan.

Saile, R., Ertl, V., Neuner, F. and Catani, C., 2014. Does war contribute to family violence against children? Findings from a two-generational multi-informant study in Northern Uganda. Child Abuse \& Neglect, 38(1): 135-146. 
Sanders, M.R., 2012. Development, evaluation, and multinational dissemination of the Triple P-Positive Parenting Program. Annual review of clinical psychology, 8: 345-379.

Sara, G. and Lappin, J., 2017. Childhood trauma: psychiatry's greatest public health challenge?. The Lancet Public Health 2017(2):300-301.

Scheidell, J.D., Quinn, K., McGorray, S.P., Frueh, B.C., Beharie, N.N., Cottler, L.B. and Khan, M.R., 2017. Childhood traumatic experiences and the association with marijuana and cocaine use in adolescence through adulthood. Addiction. Forthcoming.

Scheper-Hughes, N. and Sargent, C.F. eds., 1998. Small wars: The cultural politics of childhood. Univ of California Press.

Stempel, G.H. 2006. Scripps-Survey SHOH34. Athens, OH: Scripps Research Center, Ohio University.

Straus, M.A. 2010. Prevalence, societal causes, and trends in corporal punishment by parents in world perspective. Law and Contemporary Problems 73:1: 1-30.

Straus, M.A., Douglas, E.M. and R.A. Medeiros. 2014. The Primordial Violence: Spanking Children, Psychological Development, Violence, and Crime. Routledge: New York and London.

Straus, M.A. and Hamby, S.L., 1997. Measuring Physical \& Psychological Maltreatment of Children with the Conflict Tactics Scales.

Straus, M.A., Hamby, S.L., Finkelhor, D., Moore, D.W. and Runyan, D., 1998. Identification of child maltreatment with the Parent-Child Conflict Tactics Scales: Development and psychometric data for a national sample of American parents. Child abuse \& neglect, 22(4): 249-270.

Straus, M.A., Sugarman, D.B. and Giles-Sims, J., 1997. Spanking by parents and subsequent antisocial behavior of children. Archives of Pediatrics \& Adolescent Medicine, 151(8): 761767.

Straus, M.A. and Stewart, J.H., 1999. Corporal punishment by American parents: National data on prevalence, chronicity, severity, and duration, in relation to child and family characteristics. Clinical child and family psychology review, 2(2): 55-70.

Stoltenborgh, M., Bakermans-Kranenburg, M.J., Alink, L.R. and IJzendoorn, M.H., 2015. The prevalence of child maltreatment across the globe: Review of a series of meta-analyses. Child Abuse Review, 24(1), pp.37-50.

Twum-Danso, I. A. (2013), Children's perceptions of physical punishment in Ghana and the implications for children's rights, Childhood, 20(4) 472-486.

U.S. Department of Health \& Human Services, Administration for Children and Families, Administration on Children, Youth and Families, Children's Bureau. (2017). Child Maltreatment 2015. Available from http://www.acf.hhs.gov/programs/cb/research-datatechnology/statistics-research/child-maltreatment.

UNICEF. 2010. Child Disciplinary Practices at Home: Evidence from a Range of Low- and Middle- Income Countries. New York. 
UNICEF. 2013. Female Genital Mutilation/Cutting: A statistical overview and exploration of the dynamics of change. New York.

UNICEF. 2014. Hidden in plain sight: A statistical analysis of violence against children. New York.

$\mathrm{Vu}$, Thi Thanh Huong (2016). Understanding Children's Experiences of Violence in Viet Nam: Evidence from Young Lives, Innocenti Working Paper 2016-26, UNICEF Office of Research, Florence.

Wamoyi, J., Wight, D. and Remes, P., 2015. The structural influence of family and parenting on young people's sexual and reproductive health in rural northern Tanzania. Culture, health \& sexuality, 17(6), pp.718-732.

Webb, R.T., Antonsen, S., Carr, M.J., Appleby, L., Pedersen, C.B. and Mok, P.L., 2017. Selfharm and violent criminality among young people who experienced trauma-related hospital admission during childhood: a Danish national cohort study. The Lancet Public Health. Published online.

Whipple, E.E. and Richey, C.A., 1997. Crossing the line from physical discipline to child abuse: How much is too much?. Child abuse \& neglect, 21(5), pp.431-444.

WHO. 2002. World report on violence and health. World Health Organization. Geneva.

\footnotetext{
${ }^{i}$ Stanford Medical School maintains a useful repository of recent research on the effects of violence in childhood: http://childabuse.stanford.edu/references.html accessed 21 August 2017

ii A specific example of the definition of violence is: "The intentional use of physical force or power, threatened or actual, against oneself, another person, or against a group or community, that either results in or has a high likelihood of resulting in injury, death, psychological harm, maldevelopment or deprivation." Source: WHO (2002).

iii Further information can be found on https://www.unicef.org.uk/what-we-do/un-convention-child-rights/ accessed 7 March 2017.

iv http://www.endcorporalpunishment.org/, accessed 7 March 2017

${ }^{v}$ For a discussion of the notion of universal human rights as Western ethnocentrism see for example Renteln (2013).

${ }^{\text {vi }}$ For the full text see http://www.achpr.org/instruments/child/, accessed 26 July 2017.

vii U.S. Department of Health \& Human Services, Administration for Children and Families, Administration on Children, Youth and Families, Children's Bureau (2017) https://www.acf.hhs.gov/cb/resource/childmaltreatment-2015, accessed 7 March 2017. For for UK statistics on child homicides see Office of National Statistics,

https://www.ons.gov.uk/peoplepopulationandcommunity/crimeandjustice/compendium/focusonviolentcrimeand sexualoffences/2015-02-12/chapter2violentcrimeandsexualoffenceshomicide\#victims-aged-under-16-years, accessed 22 August 2017.

viii For most countries, detailed studies of child homicides do not exist. It is therefore difficult to establish whether the WHO figures represent an accurate estimate of the magnitude of the problem; despite this, WHO data is the most reliable source of global data currently available. One country for which a data comparison is possible is South Africa: Mathews et al (2013) conduct a detailed data compilation, by conducting a retrospective, national mortuary-based study of child homicide cases. Children were defined as persons under 18 years old, and the study period was 2009. They estimate a homicide rate of 5.5 per 100,000, higher for boys (6.9) than for girls (3.9). Keeping in mind that although the definition of children is different, this compares well to the WHO statistics for Sub-Saharan Africa, where the homicide rate is about 5 per 100,000 for 5-14yr old boys and 4.6 per 100,000 for 5-14-year-old girls.

${ }^{\text {ix }}$ For more discussion see Hoeffler (2017)
} 


\footnotetext{
${ }^{x}$ These studies do not examine the use of 'severe physical punishment' but are typically wider in scope and consider the effects of 'child maltreatment', 'abuse' and 'adverse childhood experiences'. There is no universally accepted definition of these categories and the forms of maltreatment considered may be more or less harmful than 'severe physical punishment'.

${ }^{x i}$ This appears to be one of the most commonly cited reasons for the use of corporal punishment as indicated by caregivers in Vietnam, Peru, Ethiopia and India (Thi Thanh Huong 2016; Guerrero and Rojas 2016; Pankhurst et al 2016; Morrow and Singh 2016)

xii This study is updated in Straus, Douglas and Meideros 2014: chapter 15.

xiii In order to discourage inappropriate behaviour parenting programs often advise 'time out'. This is a form of behavioural modification following problem behaviour. For a short period of time (2-10 mins) the child is removed from the area where this behaviour occurred and this removal aims to teach the child that engaging in problem behaviour will result in decreased access to reinforcing items and events. This method is also referred to as placing the child on a 'naughty step/chair'.

xiv Durrant and Smith (2010) include country case studies on the abolition of physical punishment.

${ }^{x v}$ http://www.endcorporalpunishment.org/progress/country-reports/usa.html, accessed 14 April 2017.

${ }^{x v i}$ One of the leading proponents of social learning theory is Albert Bandura, see for example Bandura (1977).

xvii Pharmaceutical licensing agreements are two-party contracts, one party is the company which developed and patented the drug and this party grants a license in the product to the other party. This other party has then the right to market the product and all drug-related technology for commercial use.
} 